\title{
Covid-19 and breastfeeding: what's the risk?
}

\author{
Ivan L. Hand $\mathbb{B}^{1} \cdot$ Lawrence Noble $\mathbb{B}^{2}$
}

Received: 15 May 2020 / Revised: 15 June 2020 / Accepted: 7 July 2020 / Published online: 13 July 2020

(c) Springer Nature America, Inc. 2020

The United States has been severely affected by the coronavirus disease 2019 (Covid-19) pandemic. A disaster, whether natural or man-made, often deprives people of the necessary resources needed to survive. The prevalence of food insecurity in the US was $11.1 \%$ in 2018 , with food insecurity among children in $7.1 \%$ of households [1]. With growing unemployment and sporadic food shortages this can only worsen. As a general rule, breastfeeding provides the cleanest and safest form of infant and young child nutrition in disaster situations and is the normative standard for infant nutrition [2].

Breastfeeding provides milk that is the most appropriate nutrition, readily available without dependence on the purchase of supplies. Breastmilk, with its anti-infective and anti-inflammatory factors, becomes especially important in mitigating infectious conditions. Influenza serves as a potential model for the way breastmilk may serve to protect the infant. If the mother is infected, her milk may provide antibodies against that specific infection. In a study of mothers immunized against influenza, specific milk IgA concentrations were high for as long as 6 months [3]. Infants of these mothers also exhibited less respiratory illness with fever. Breastfeeding also appears to be associated with an increased production of type I interferon in infants infected with influenza virus [4]. This response is part of an innate antiviral response to influenza, not seen with respiratory syncytial virus or human metapneumovirus. In a study of 26 adult Covid-19 patients in an ICU setting, it was shown that interferon production was impaired in $\sim 20 \%$ of patients and these patients all had poorer outcomes with

Ivan L. Hand

ivan.hand@nychhc.org

1 Division of Neonatology, Department of Pediatrics, New York City Health + Hospitals/Kings County, Brooklyn, NY, USA

2 Division of Neonatology, Department of Pediatrics, New York City Health + Hospitals/Elmhurst, Icahn School of Medicine at Mount Sinai, Queens, NY, USA longer ICU stays and greater need for invasive ventilation [5]. In a similar study, it was shown that critically ill Covid19 patients had a profoundly impaired type I interferon response, despite comparable viral loads to milder cases [6]. A recent report found a strong SIgA antibody SARS-CoV-2 immune response in breastmilk from 12 out of 15 mothers (80\%) previously infected with Covid-19 [7].

Breastfeeding allows the mother to independently provide for her child despite the helplessness that occurs during a disaster. Infant formula, bottles and other feeding supplies may not be available due to shortages or panic buying [8]. Errors in formula preparation can occur at any time, especially during the chaos of a disaster. Therefore, the goal of infant disaster relief and the best way to save vulnerable infants must be to protect the breastfeeding relationship and to help women to breastfeed. There is very limited data on the presence of Covid-19 in breastmilk and the possibility of mother-infant transmission. In a small study of six mothers with Covid-19, breastmilk samples were collected and tested after the first lactation [9]. Samples were tested for Covid-19 using qRT-PCR with results demonstrating that all tests were negative. A slightly larger study of 19 mothers did not find SARS-CoV-2 in breastmilk [10], as did other small studies [11-14]. This is similar to past reports on the Severe Acute Respiratory Syndrome related coronavirus (SARS) where the virus did not seem to be vertically transmitted although breastmilk samples were not obtained or analyzed $[15,16]$. Of note, breastmilk of a pregnant woman who contracted a severe case of SARS in the second trimester, was negative for SARS PCR, but did contain antibodies to SARS, at 130 days after the infection onset [17]. However, there have been three published case reports of the presence of Covid-19 RT-PCR in breastmilk samples [18-20]. In these reports, analysis of breastmilk from six women identified Covid-19 RT-PCR in three women's milk, although both women's breastmilk became negative for Covid-19 by days 3,14, and 14, respectively. One infant tested positive for Covid-19, however, it remains unclear if the infected was infected from breastmilk. The infants were all clinically well. 
Maternal-infant transmission of infection and its effects on neonatal and infant outcomes is a major concern. A few small case series suggest that perinatal transmission to newborns from infected women may occur, likely Infrequently $[9,21,22]$. There is some data that infants under 1 year of age are at risk for disease although this still is a relatively rare outcome. New York City, which has been severely hit by the virus, to May 27, 2020 has had 197,000 cases and 16,600 deaths confirmed to be from COVID-19, but only, 5370 cases (2\%) and 10 deaths in children aged 0 17 years [23]. In the United States, $1.7 \%$ of confirmed cases of Covid-19 were among persons aged $<18$ years and $0.27 \%$ in infants $<1$ year [24]. A series of 33 Covid positive women who delivered in China, 3 of the infants were also positive and symptomatic, 2 had mild symptoms and the third was a 31 week preterm, whose symptoms were probably from prematurity. All three were separated from their mother at birth and did not breastfeed [21]. A recent report from Italy described two maternal-infant dyads who presented with positive nasopharyngeal swabs for SARSCoV-2 at 10 and 18 days after birth [25]. None needed ICU care, one infant was asymptomatic and one had cough, diarrhea, and poor feeding. The breastmilk of both mothers was negative for SARS-CoV-2 and they hypothesized that the mothers and infants were probably infected by a third person at the same time. A 13-month-old breastfeeding infant was reported in China with fever, occasional dry cough, and nasal congestion at the same time his mother was ill, both were diagnosed with Covid-19. SARS-CoV-2 nucleic acid was not detected in the breastmilk, but antibodies against SARS-CoV-2 were. Again, there was no evidence of mother-to-child transmission of the virus through breastfeeding and both were exposed to a relative with Covid-19 [26].

Due to limited data concerning maternal-infant transmission of Covid-19, there are varying guidelines on how to manage delivery and immediate newborn care of mothers with or suspected of Covid-19. Many centers have chosen to universally screen mothers given the high rates of asymptomatic disease in the community along with the need to cohort Covid positive and negative patients. The AAP and $\mathrm{CDC}$, although strongly supporting breastfeeding and breastmilk, has taken the approach of recommending to temporarily separate infants from infected mothers in the hospital $[27,28]$. The WHO does not recommend separation of infants from their mothers, rather they recommend skin to skin, rooming in and encourage exclusive breastfeeding [29]. All recommend that mothers who room-in or breastfeed should follow strict hand washing and use of masks. All also recommend that the expressed breastmilk of these mothers to be fed to their infants.

In conclusion, there remains a great deal to learn about the behavior of this virus as well as mother to infant transmission. Future guidance on separating infants and mothers need to consider not just the risks of the virus, but also the risks to breastfeeding.

\section{Compliance with ethical standards}

Conflict of interest The authors declare that they have no conflict of interest.

Publisher's note Springer Nature remains neutral with regard to jurisdictional claims in published maps and institutional affiliations.

\section{References}

1. Coleman-Jensen ARM, Gregory C, Singh A. Household Food Security in the United States in 2018. ERR-270, US Department of Agriculture. Economic Research Service; 2019.

2. Barfield WD, Krug SE. Disaster Preparedness in Neonatal Intensive Care Units. Pediatrics. 2017;139:e20170507.

3. Schlaudecker EP, Steinhoff MC, Omer SB, McNeal MM, Roy E, Arifeen SE, et al. IgA and neutralizing antibodies to influenza a virus in human milk: a randomized trial of antenatal influenza immunization. PloS One 2013;8:e70867.

4. Melendi GA, Coviello S, Bhat N, Zea-Hernandez J, Ferolla FM, Polack FP. Breastfeeding is associated with the production of type I interferon in infants infected with influenza virus. Acta Paediatr. 2010;99:1517-21.

5. Trouillet-Assant S, Viel S, Gaymard A, Pons S, Richard JC, Perret $\mathrm{M}$, et al. Type I IFN immunoprofiling in COVID-19 patients. J Allergy Clin Immunol. 2020;146:206-8.

6. Gruber C. Impaired interferon signature in severe COVID-19. Nat Rev Immunol. 2020;20:353.

7. Fox A, Marino J, Amanat F, Krammer F, Hahn-Holbrook J, ZollaPazner S, et al. Evidence of a significant secretory-IgA dominant SARS-CoV-2 immune response in human milk following recovery from COVID-19. medRxiv 2020; https://doi.org/10.1101/ 2020.05.04.20089995.

8. New York Times. https://www.nytimes.com/2020/03/30/parenting/ coronavirus-baby-formula-shortages-wipes-diapers.html. 2020.

9. Chen H, Guo J, Wang C, Luo F, Yu X, Zhang W, et al. Clinical characteristics and intrauterine vertical transmission potential of COVID-19 infection in nine pregnant women: a retrospective review of medical records. Lancet. 2020;395:809-15.

10. Liu W, Wang J, Li W, Zhou Z, Liu S, Rong Z. Clinical characteristics of 19 neonates born to mothers with COVID-19. Front Med. 2020;14:193-8.

11. Fan C, Lei D, Fang C, Li C, Wang M, Liu Y, et al. Perinatal transmission of COVID-19 associated SARS-CoV-2: should we worry? [published online ahead of print, 2020 Mar 17]. Clin Infect Dis. 2020;ciaa226. https://doi.org/10.1093/cid/ciaa226.

12. Li Y, Zhao R, Zheng S, Chen X, Wang J, Sheng X, et al. Lack of vertical transmission of severe acute respiratory syndrome coronavirus 2, China. Emerg Infect Dis. 2020;26:1335-6.

13. Schwartz DA. An analysis of 38 pregnant women with COVID19, their newborn infants, and maternal-fetal transmission of SARS-CoV-2: maternal coronavirus infections and pregnancy outcomes. Arch Pathol Lab Med. 2020. https://doi.org/10.5858/a rpa.2020-0901-SA. [published online ahead of print].

14. Wang S, Guo L, Chen L, Liu W, Cao Y, Zhang J, et al. A case report of neonatal COVID-19 infection in China. Clin Infect Dis. 2020. https://doi.org/10.1093/cid/ciaa225. [published online ahead of print]. 
15. Shek CC, Ng PC, Fung GP, Cheng FW, Chan PK, Peiris MJ, et al. Infants born to mothers with severe acute respiratory syndrome. Pediatrics. 2003;112:e254.

16. Wong SF, Chow KM, Leung TN, Ng WF, Ng TK, Shek CC, et al. Pregnancy and perinatal outcomes of women with severe acute respiratory syndrome. Am J Obstet Gynecol. 2004;191:292-7.

17. Robertson CA, Lowther SA, Birch T, Tan C, Sorhage F, Stockman L, et al. SARS and pregnancy: a case report. Emerg Infect Dis. 2004;10:345-8.

18. Buonsenso D, Costa S, Sanguinetti M, Cattani P, Posteraro B, Marchetti S, et al. Neonatal late onset infection with severe acute respiratory syndrome coronavirus 2. Am J Perinatol. 2020;37:869-72.

19. Wu Y, Liu C, Dong L, Zhang C, Chen Y, Liu J, et al. Coronavirus disease 2019 among pregnant Chinese women: case series data on the safety of vaginal birth and breastfeeding. BJOG. 2020. https:// doi.org/10.1111/1471-0528.16276. [published online ahead of print].

20. Gross R, Conzelmann C, Muller JA, Stenger S, Steinhart K, Kirchhoff F, et al. Detection of SARS-CoV-2 in human breastmilk. Lancet. 2020;395:1757-8.

21. Zeng L, Xia S, Yuan W, Yan K, Xiao F, Shao J, et al. Neonatal early-onset infection with SARS-CoV-2 in 33 neonates born to mothers with COVID-19 in wuhan, China. JAMA Pediatr. 2020;174:722-5.
22. Zhu H, Wang L, Fang C, Peng S, Zhang L, Chang G, et al. Clinical analysis of 10 neonates born to mothers with 2019-nCoV pneumonia. Transl Pediatr 2020;9:51-60.

23. NYS Department of Health. https://www1.nyc.gov/assets/doh/ downloads/pdf/imm/covid-19-daily-data-summary-05072020-1. pdf. 2020.

24. Centers for Disease Control. Coronavirus Disease 2019 in Children-United States, February 12-April 2, 2020. MMWR Morb Mortal Wkly Rep. 2020;69:422-6.

25. Salvatori G, De Rose DU, Concato C, Alario D, Olivini N, Dotta A, et al. Managing COVID-19-positive maternal-infant dyads: an Italian experience. Breastfeeding Med. 2020;15:347-8.

26. Yu Y, Jion X, Li Y, Hu Y, Li B. Breast milk-fed infant of COVID-19 pneumonia mother: a case report. https://www.resea rchsquarecom/article/rs-20792/v1. 2020.

27. American Academy of Pediatrics. AAP FAQs: management of infants born to mothers with suspected or confirmed COVID-19. Am Acad Pediatr. 2020.

28. Centers for Disease Control. www.cdc.gov/coronavirus/2019ncov/hcp/inpatient-obstetric-healthcare-guidance.html. 2020.

29. World Health Organization. www.who.int/emergencies/diseases/ novel-coronavirus-2019/question-and-answers-hub/q-a-detail/q-aon-covid-19-pregnancy-and-childbirth. 2020. 